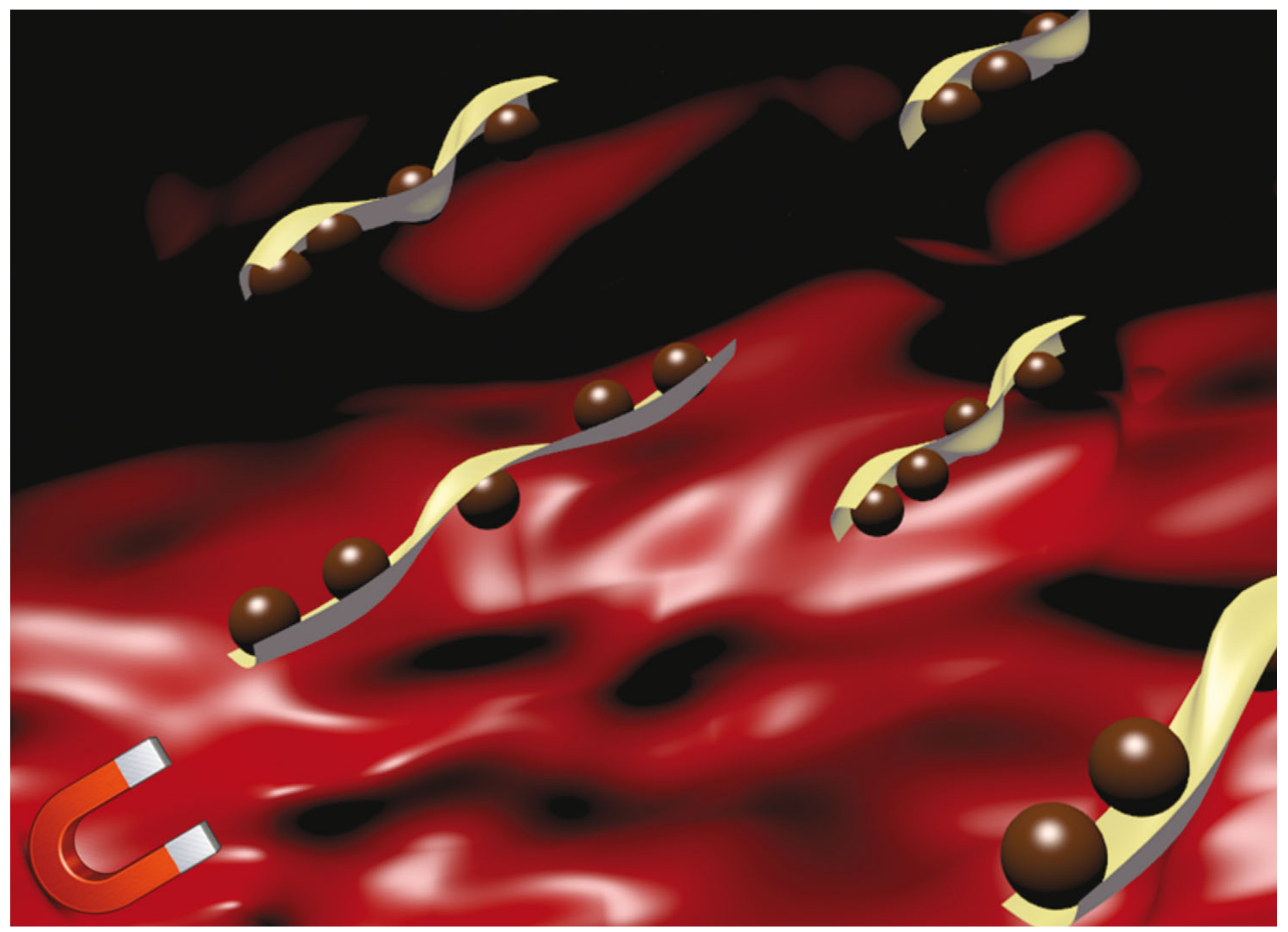

Highlighting research results from the Davies Group (warwick.ac.uk/daviesgroup), Department of Chemistry, University of Warwick, UK.

Heparin-stabilised iron oxide for MR applications: a relaxometric study

Iron oxide nanoparticles have strong potential as MRI contrast agents, though their popularity has plummeted in recent years, due to low efficacy and safety concerns, including haemagglutination. There is therefore a real need for new contrast agents with excellent MRI capabilities and biocompatibility. This work describes the preparation of heparin-stabilised iron oxide nanoparticles with extremely strong MRI contrast behaviour at clinically-relevant and low field strengths which outperform current clinical standards. The stable colloidal nanoparticles further efficiently prevent protein-adsorption triggered thrombosis and show strong potential as the next generation of MRI contrast agents.

\section{As featured in:}

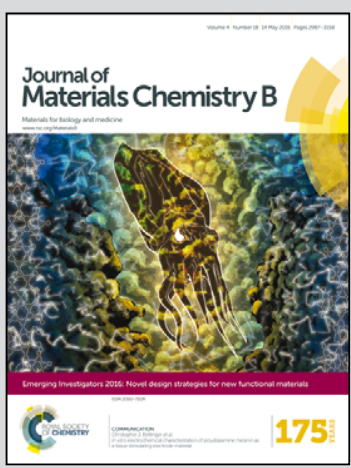

See Gemma-Louise Davies et al., J. Mater. Chem. B, 2016, 4, 3065.

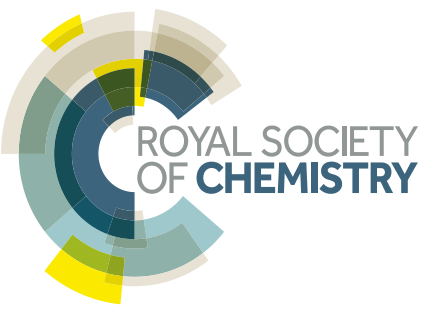




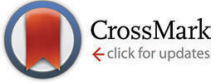

Cite this: J. Mater. Chem. B, 2016 4, 3065

Received 4th April 2016

Accepted 15th April 2016

DOI: $10.1039 / c 6 t b 00832 a$

www.rsc.org/MaterialsB

\title{
Heparin-stabilised iron oxide for MR applications: a relaxometric study $\dagger$
}

\author{
Lucy Ternent, ${ }^{a}$ Daniel Alexander Mayoh, ${ }^{\mathrm{b}}$ Martin Richard Lees ${ }^{\mathrm{b}}$ and \\ Gemma-Louise Davies*c
}

\begin{abstract}
Superparamagnetic nanoparticles have strong potential in biomedicine and have seen application as clinical magnetic resonance imaging (MRI) contrast agents, though their popularity has plummeted in recent years, due to low efficacy and safety concerns, including haemagglutination. Using an in situ procedure, we have prepared colloids of magnetite nanoparticles, exploiting the clinically approved anti-coagulant, heparin, as a templating stabiliser. These colloids, stable over several days, produce exceptionally strong MRI contrast capabilities particularly at low fields, as demonstrated by relaxometric investigations using nuclear magnetic resonance dispersion (NMRD) techniques and single field $r_{1}$ and $r_{2}$ relaxation measurements. This behaviour is due to interparticle interactions, enhanced by the templating effect of heparin, resulting in strong magnetic anisotropic behaviour which closely maps particle size. The nanocomposites have also reliably prevented protein-adsorption triggered thrombosis typical of non-stabilised nanoparticles, showing great potential for in vivo MRI diagnostics.
\end{abstract}

\section{Introduction}

Magnetic Resonance Imaging (MRI) is an important noninvasive tool in medical diagnostics. ${ }^{1}$ Contrast agents (CAs) are often applied to improve signal contrast and work by decreasing the $T_{1}$ or $T_{2}$ relaxation times of the indigenous water present in the body through close interactions. Such interactions are governed by physical parameters, including hydration number $(q)$, rotational correlation time $\left(\tau_{\mathrm{R}}\right)$, water residence lifetime $\left(\tau_{\mathrm{m}}\right)$ and diffusional correlation time $\left(\tau_{\mathrm{D}}\right)$, amongst others, which have previously been described in detail using the Solomon, Bloembergen and Morgan (SBM) theory. ${ }^{2-4}$ Positive CAs, based on paramagnetic $\mathrm{Gd}^{3+}$ ions are the clinical standard, providing hyperintensive areas of signal which are diagnostically useful. ${ }^{1,3}$ Iron oxide, usually in the form of superparamagnetic magnetite nanoparticles, is a common negative contrast agent in MR imaging, producing areas of hypointensive signal. ${ }^{4,5}$

Magnetite nanoparticles have seen commercial use as MRI CAs for a number of years, for example, Feridex ${ }^{\circledR}$ and Resovist ${ }^{\circledR}$. These commercial formulations are stabilised magnetic fluids

\footnotetext{
${ }^{a}$ Molecular Organisation and Assembly in Cells Doctoral Training Centre, Coventry House, University of Warwick, Coventry CV4 7AL, UK

${ }^{b}$ Department of Physics, University of Warwick, Gibbet Hill Road, Coventry CV4 7AL, UK

${ }^{c}$ Department of Chemistry, University of Warwick, Gibbet Hill Road, Coventry CV4 7AL, UK. E-mail: g-l.davies@warwick.ac.uk; Fax: +02476 524803; Tel: +02476151828

$\dagger$ Electronic supplementary information (ESI) available: Table S1. See DOI: $10.1039 /$ c6tb00832a
}

composed of aggregates of magnetite nanoparticle cores with polymer (e.g. dextran) coating.s. ${ }^{4,6}$ In recent years, however their popularity in the clinic has plummeted, due to low efficacy and safety concerns. Nevertheless, they remain popular in research, as they are widely accepted to pose a low cytotoxic risk for mammalian cell lines and hosts. ${ }^{5,7}$

The key features of high signal contrast nanoparticulate MRI CAs include excellent colloidal stability, along with strong magnetic properties, well-hydrated surfaces and biocompatibilityphysical properties which are strongly linked to nanoparticle size and architecture of assemblies. ${ }^{4,8}$ Poor aqueous colloidal stability inevitably results in agglomeration, an effect known to lead to rapid clearance from blood circulation and unexpected responses, including haemagglutination in the body. ${ }^{9}$ The incorporation of stabilising agents has therefore been adopted to engender the appropriate long-term stability required of a medical contrast agent. ${ }^{10}$ In situ incorporation of a stabiliser during the preparation of iron oxide nanoparticles provides one of the best approaches to long term stability, which can also enhance the magnetic response of colloidal particles, and hence their MR contrast capabilities. ${ }^{10,11}$ The use of block copolymers or charged polyelectrolyte species (e.g. DNA or DNA-mimics, such as poly(sodium-4-styrene) sulfonate (PSSS)) during the synthesis of magnetite nanoparticles has been observed to provide stable magnetic fluids with enhanced magnetic resonance properties. ${ }^{10,12-15}$

Dispersive nuclear magnetic resonance (NMRD) is a useful tool in the analysis of the relaxation properties of colloidal magnetic nanoparticles. ${ }^{8,16}$ It can provide a quantitative assessment of the potential usefulness of a CA species in the clinical 
MRI frequency range (10-60 MHz). NMRD uses SBM theory to describe the relaxation rate of a suspending medium and the effect of a CA on it. ${ }^{17}$ Specifically, it provides information about the relaxation behaviour of ${ }^{1} \mathrm{H}$ spins in a system, through the measurement of water relaxation rate enhancement per mmol of CA, or spin-lattice relaxivity, $r_{1}$, defined by eqn (1), as a function of magnetic field strength (or flux density, $B_{0}$ ).

$$
r_{1}=\frac{\left(R_{1 \text { sample }}-R_{1 \text { water }}\right)}{[\mathrm{CA}]}
$$

where $R_{1 \text { sample }}$ is the measured relaxation rate of a nanoparticle suspension (where $R_{1}=1 / T_{1}$ ) and $R_{1 \text { water }}$ is the measured relaxation rate of water in the absence of a CA. [CA] represents the total millimolar concentration of active CA species (in the case of magnetite nanoparticles, iron).

The choice of stabilising agent is crucial, not only on influencing the relaxation efficiency and subsequent stability of the magnetic fluid, but also on pharmacokinetics, behaviour and biocompatibility with human cells and physiology. Surface coating of nanoparticles with some agents (e.g. polymers, including polyethylene glycol) has been shown to inhibit opsonisation and delay phagocytosis by the mononuclear phagocyte system (MPS), which is beneficial for increasing blood circulation times. ${ }^{9,18,19}$ Dextran is a popular stabilising agent; however, despite being Food and Drug Administration (FDA) approved and regularly used clinically, it provides poorly defined magnetic fluids and several contrast agents utilising this polymer have been withdrawn from the market in recent years (e.g. Sinerem $\left.{ }^{\circledR}\right)$ due to poor efficacy. There is therefore a real need for new CA species with excellent MRI contrast capabilities which are also biocompatible.

Heparin is an FDA approved linear glycosaminoglycan which is highly charged and is regularly used clinically as an anticoagulant. $^{20}$ Its negatively charged backbone (Scheme 1), its strong biocompatibility, coupled with its ability, when immobilised onto nanoparticle surfaces, to dramatically reduce the rate of phagocytic uptake (evading the MPS), reduce opsonisation in culture and prevent agglomeration due to its strongly hydrophilic surface, make it an ideal candidate as a magnetic nanoparticle stabilising agent. ${ }^{18}$ Positively charged stabilised iron oxide particles, on the other hand, have been shown to have a higher cytotoxic effect on cells and animal models than negatively charged analogues. ${ }^{21}$ Some reports of heparin-stabilised magnetic nanoparticles have demonstrated their usefulness in the labelling of human mesenchymal stem cells and cell tracking, ${ }^{22}$ drug delivery, ${ }^{23,24}$ labelling and imaging of pancreatic islets, ${ }^{25}$ with

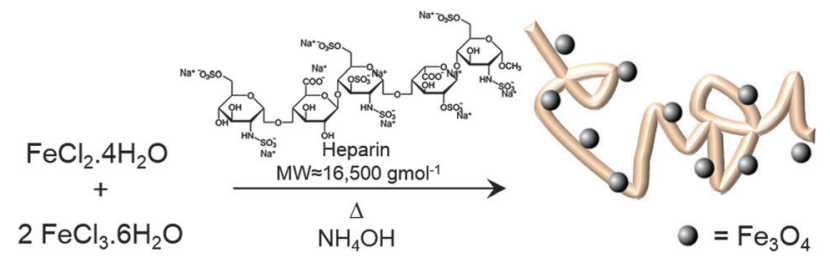

Scheme 1 Representation of the in situ preparation of heparin-stabilised $\mathrm{Fe}_{3} \mathrm{O}_{4}$ nanoparticles. some of these demonstrating excellent $T_{2}$-weighted (in vivo) MRI of tissues and cells, ${ }^{26-28}$ indicating that such stabilised systems are promising as MRI CAs. There have not, however, been any studies to date which describe in detail the importance of precise composition of the magnetic fluid (in terms of molar reactant ratios) on their magnetic resonant properties.

Herein, we aim to produce a family of heparin-stabilised magnetite nanoparticles, prepared through the variation of reagent ratios using an in situ approach, and determine their relaxometric characteristics utilising variable field relaxation (NMRD) and single field relaxation studies. The particles will also be assessed for their anti-thrombotic/haemagglutination behaviour (if any).

\section{Results and discussion}

\section{Physical and structural behaviour}

Heparin-stabilised $\mathrm{Fe}_{3} \mathrm{O}_{4}$ nanoparticles were prepared in a one pot in situ synthesis, by co-precipitating $\mathrm{Fe}^{\mathrm{II}}$ and $\mathrm{Fe}^{\mathrm{III}}$ salts in a $1: 2$ molar ratio in the presence of heparin (Scheme 1) at varying molar ratios of iron: heparin, as detailed in Table 1 and the Experimental section. Using this approach, the polyelectrolyte species behaves as a templating agent (vide infra), producing magnetic fluids of stabilised magnetite nanoparticles.

Phase identity was confirmed using X-ray diffraction (XRD); patterns were in good agreement with the reported structure for inverse spinel cubic magnetite (Fig. 1). ${ }^{29}$ Raman spectra (Fig. 2) recorded for all composites display peaks at 670 and $190 \mathrm{~cm}^{-1}$, which are representative of the $\mathrm{A}_{1 \mathrm{~g}}$ and $\mathrm{T}_{2 \mathrm{~g}}$ modes of magnetite respectively; broad peaks centred at 340 and $500 \mathrm{~cm}^{-1}$ represent $\mathrm{E}_{\mathrm{g}}$ and $\mathrm{T}_{2 \mathrm{~g}}$ modes of magnetite. These appear with relatively high intensities due to an overlap with $T_{1}$ and $\mathrm{E}$ modes of maghemite impurities in the sample. ${ }^{30-32}$ The presence of maghemite in the samples is likely to be due to oxidation of the sample during measurement due to heating from the high intensity of the laser.

Infrared (IR) spectroscopy (Fig. 3) shows non-stabilised $\mathrm{Fe}_{3} \mathrm{O}_{4}$ nanoparticles with bands between $3600-3100 \mathrm{~cm}^{-1}$ representing $\mathrm{OH}$ stretching vibrations from surface hydroxyl groups and physisorbed water groups, in-plane and out-of-plane OH stretching between $1110-1090 \mathrm{~cm}^{-1}$ and $1070-1030 \mathrm{~cm}^{-1}$ and the stretch between $670-500 \mathrm{~cm}^{-1}$ representing $\mathrm{Fe}-\mathrm{O}$ (bands labelled and highlighted in yellow, Fig. 3). ${ }^{14}$ The IR spectrum of heparin shows bands representing asymmetric and symmetric $\mathrm{COO}^{-}$stretching (1660-1530 and 1440-1400 $\mathrm{cm}^{-1}$ ), asymmetric and symmetric $\mathrm{O}=\mathrm{S}=\mathrm{O}$ stretching (1380-1350 and 1310-1190 $\mathrm{cm}^{-1}$ ), symmetric and asymmetric $\mathrm{C}-\mathrm{O}-\mathrm{C}$ stretching (1170-1130 and 1050-950 $\left.\mathrm{cm}^{-1}\right)$, asymmetric and symmetric S-O-C stretching (910-880 and $\left.870-840 \mathrm{~cm}^{-1}\right), \mathrm{C}-\mathrm{H}$ bending (1490-1450 $\mathrm{cm}^{-1}$ ) and $\mathrm{N}-\mathrm{H}$ wagging $\left(820-800 \mathrm{~cm}^{-1}\right)$ vibrations (bands labelled and highlighted in grey, Fig. 3). Stretches representing $\mathrm{Fe}_{3} \mathrm{O}_{4}$ and heparin can be observed in the heparin-stabilised samples 1-5, these correspond well with the non-stabilised sample and heparin reagent spectra (as highlighted in Fig. 3). There is some shifting $\left(<100 \mathrm{~cm}^{-1}\right.$ shifts, highlighted with striped grey bars in Fig. 3) in the frequency of stretches 
Table 1 Reagent ratios and sample characteristics of non-stabilised and heparin-stabilised $\mathrm{Fe}_{3} \mathrm{O}_{4}$ nanoparticles

\begin{tabular}{|c|c|c|c|c|c|c|c|}
\hline & {$[\mathrm{Fe}]^{a}(\mathrm{mM})$} & ${\left[\text { Heparin }^{a}(\mathrm{mM})\right.}$ & $\begin{array}{l}{[\mathrm{Fe}]:[\text { Heparin }] \text { ratio }^{a}} \\
(\sim \text { monomer ratio })\end{array}$ & $d_{\text {hyd }}^{b}(\mathrm{~nm})[\mathrm{PDI}]$ & $\zeta$-pot. ${ }^{b}(\mathrm{mV})$ & $d_{\text {core }}^{c}(\mathrm{~nm})$ & $M_{\mathrm{s}}^{d}\left(\mathrm{emu} \mathrm{g}^{-1}\right)$ \\
\hline $\mathrm{Fe}_{3} \mathrm{O}_{4}$ & - & - & - & - & - & $8.9 \pm 2.5$ & $72.1 \pm 0.1$ \\
\hline 1 & 50 & 0.008 & 6250 (595) & $43.5 \pm 0.3[0.158]$ & $-26.5 \pm 0.8$ & $9.0 \pm 1.3$ & $69.2 \pm 0.1$ \\
\hline 3 & 50 & 0.02 & $2500(238)$ & $57.2 \pm 0.3[0.123]$ & $-31.2 \pm 0.4$ & $8.9 \pm 1.2$ & $67.3 \pm 0.1$ \\
\hline 4 & 30 & 0.02 & $1500(143)$ & $88.3 \pm 0.6[0.197]$ & $-33.2 \pm 0.1$ & $7.7 \pm 1.0$ & $66.5 \pm 0.1$ \\
\hline 5 & 30 & 0.30 & $100(9.5)$ & $103.2 \pm 0.3[0.162]$ & $-36.8 \pm 0.8$ & $6.7 \pm 1.1$ & $56.4 \pm 0.1$ \\
\hline
\end{tabular}

${ }^{a}$ Total initial concentration of reagents. ${ }^{b}$ Hydrodynamic diameter $\left(d_{\text {hyd }}\right)$, zeta potential $(\zeta$-pot.) and polydispersity index (PDI) calculated from dynamic light scattering. ${ }^{c} d_{\text {core }}$ average particle size calculated from $>100$ particles as analysed from transmission electron microscope images. ${ }^{d}$ Magnetic saturation at $20 \mathrm{kOe}\left(M_{\mathrm{s}}\right)$, measured per total mass of sample.

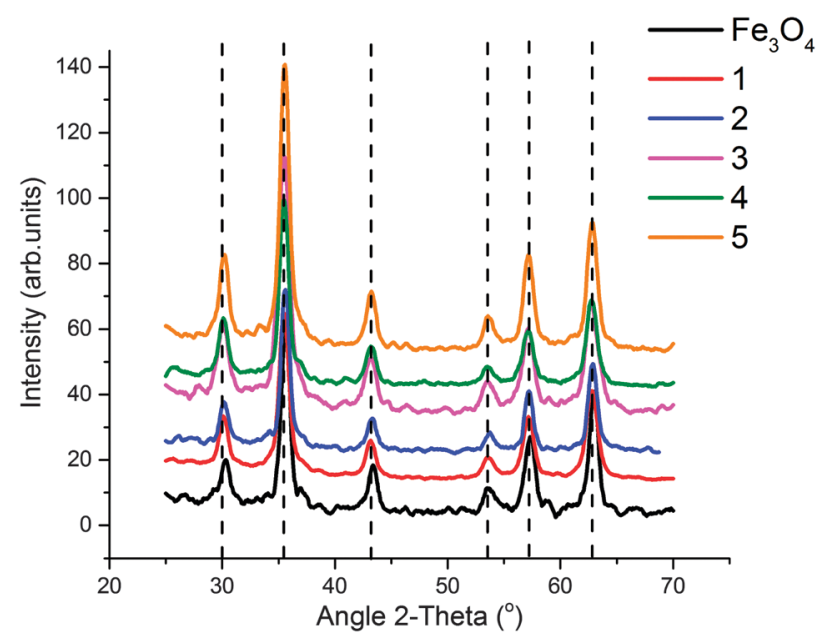

Fig. 1 XRD patterns of non-stabilised $\mathrm{Fe}_{3} \mathrm{O}_{4}$ and heparin-stabilised $\mathrm{Fe}_{3} \mathrm{O}_{4}$ nanoparticles 1-5, prepared according to Table 1. Dashed lines represent expected peak positions for cubic magnetite according to the JCPDS database.

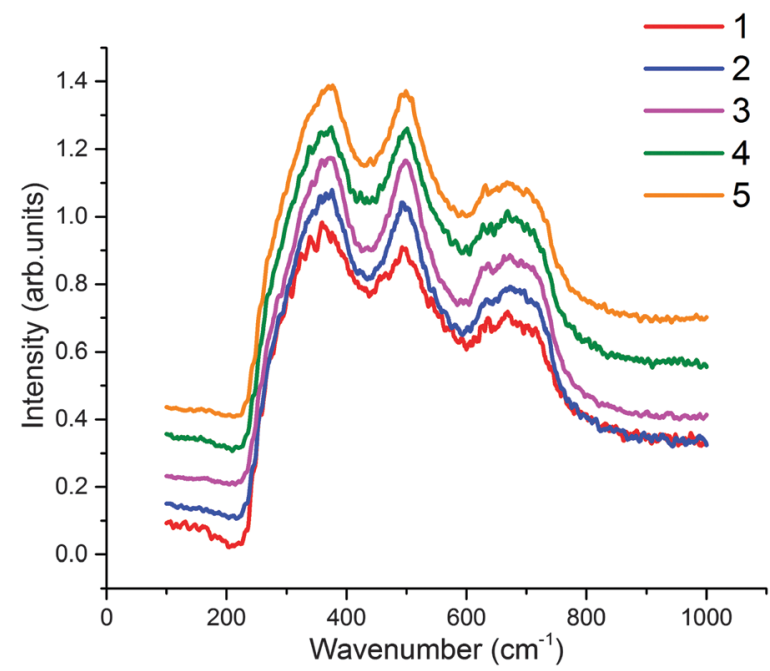

Fig. 2 Raman spectra of heparin-stabilised $\mathrm{Fe}_{3} \mathrm{O}_{4}$ nanoparticles 1-5, prepared according to Table 1.

representing sulfonate groups $(\mathrm{O}=\mathrm{S}=\mathrm{O}$ and $\mathrm{S}-\mathrm{O}-\mathrm{C})$, which is due to the interaction of these groups with the $\mathrm{Fe}_{3} \mathrm{O}_{4}$ particle surfaces. ${ }^{33}$
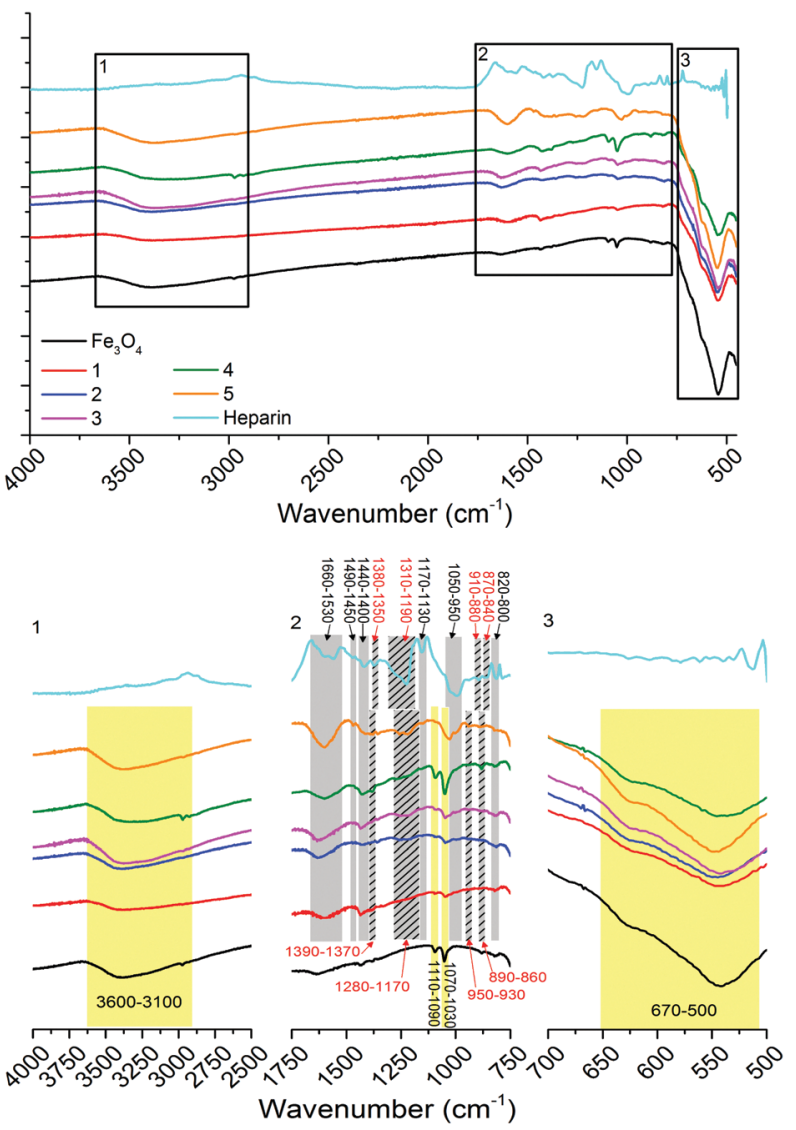

Fig. 3 IR spectra of non-stabilised $\mathrm{Fe}_{3} \mathrm{O}_{4}$ nanoparticles, heparin and heparinstabilised $\mathrm{Fe}_{3} \mathrm{O}_{4}$ nanoparticles 1-5, prepared according to Table 1, as labelled (top). Black squares are zoomed in (bottom, as labelled) with bands labelled and highlighted: yellow for stretches associated with $\mathrm{Fe}_{3} \mathrm{O}_{4}$, grey for those associated with heparin, with shifted stretches due to association of heparin with particles highlighted by striped grey bars and red text.

Magnetometry was performed on all solid samples prepared (Fig. 4). Non-stabilised $\mathrm{Fe}_{3} \mathrm{O}_{4}$ nanoparticles possessed a magnetic saturation value at $20 \mathrm{kOe}\left(M_{\mathrm{s}}\right)$ of $72.1 \pm 0.1 \mathrm{emu} \mathrm{g}^{-1}$. This is slightly lower than reported for bulk magnetite $\left(92 \mathrm{emu} \mathrm{g}^{-1}\right)$, however the value obtained is comparable to reported values for magnetite formed in this manner. ${ }^{34-36}$ Heparin-stabilised samples had $M_{\mathrm{s}}$ values varying between $56-70 \mathrm{emu}^{-1}$ $\left(M_{\mathrm{S}}\right.$ measured per total mass of sample; Table 1), with values decreasing with increasing heparin content in samples, as expected 


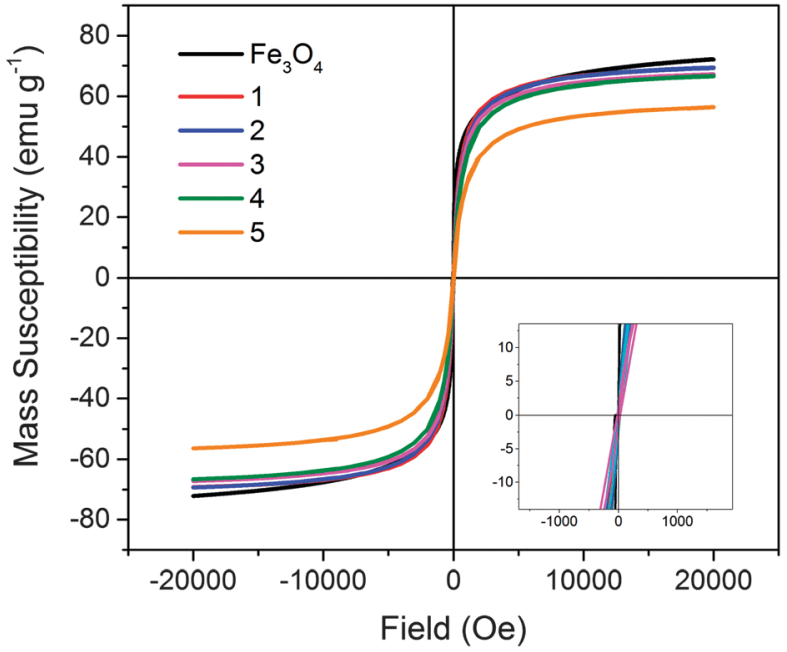

Fig. 4 Magnetisation (mass susceptibility) versus field profiles of nonstabilised $\mathrm{Fe}_{3} \mathrm{O}_{4}$ and heparin-stabilised $\mathrm{Fe}_{3} \mathrm{O}_{4}$ nanoparticles 1-5, prepared according to Table 1.

due to the mass contribution of the non-magnetic polymer component. All samples demonstrated typical superparamagnetic characteristics, indicating that the presence of heparin during the co-precipitation procedure did not negatively affect the resulting magnetite nanoparticles.

The stable aqueous colloids (final washings - see Experimental section) were characterised by transmission electron microscopy (TEM, Table 1 and Fig. 5) and dynamic light scattering (DLS, Table 1 and Fig. 6) and NMRD analysis (Fig. 7). Fig. 5 shows the presence of discrete nanoparticles which exist as aggregates in the absence of a magnetic field. The primary particle size $\left(d_{\text {core }}\right)$ increases with increasing metal to polyelectrolyte ratio (Table 1), indicating increased primary particle growth due to the presence of increased amounts of iron. ${ }^{13}$

Nanoparticle samples which were dried (on TEM grids) in the presence of an external permanent parallel magnetic field demonstrated strong parallel 1-dimensional linear alignment
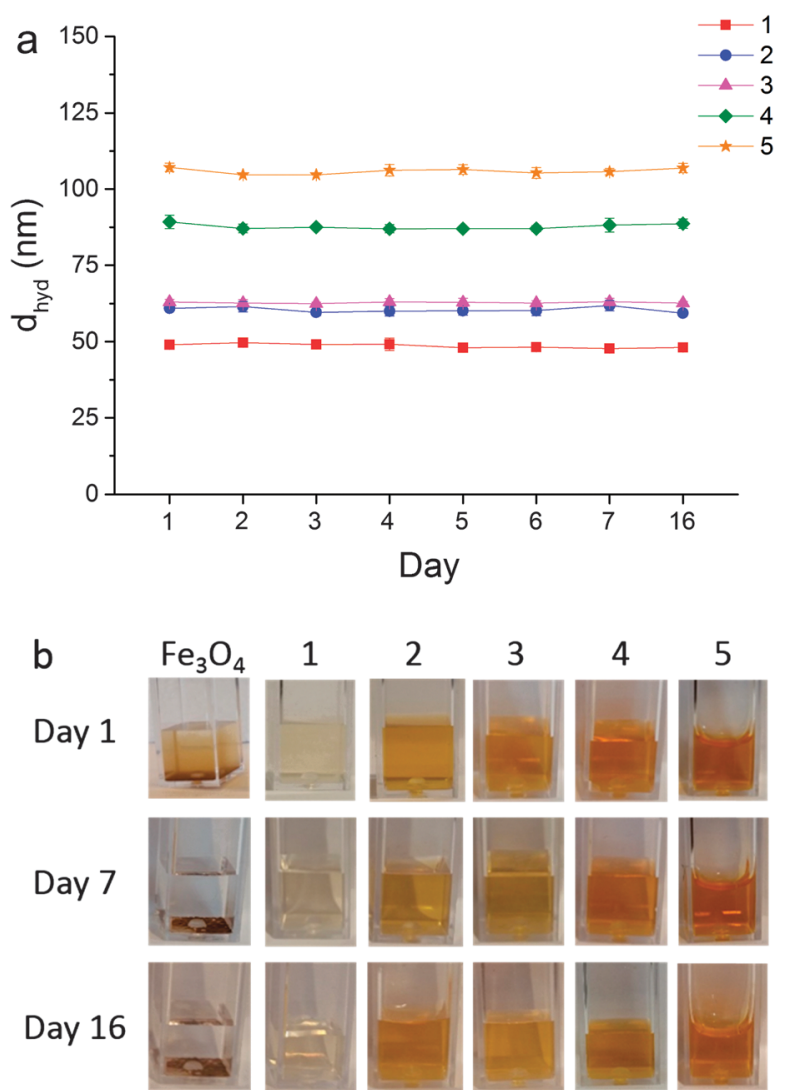

Fig. 6 (a) Hydrodynamic diameters ( $d_{\text {hyd }}$ ) of heparin-stabilised $\mathrm{Fe}_{3} \mathrm{O}_{4}$ nanoparticles 1-5, prepared according to Table 1, recorded over several days showing negligible changes in size; (b) photographs of samples over several days illustrating precipitation of non-stabilised $\mathrm{Fe}_{3} \mathrm{O}_{4}$ and stability of heparin-stabilised samples $1-5$, as labelled.

along the field axis (Fig. 5). This behaviour is not unexpected, as in addition to their role as stabilising agents, helping to overcome particle aggregation in suspension, polyelectrolytes are well-known to behave as templating species. The negatively
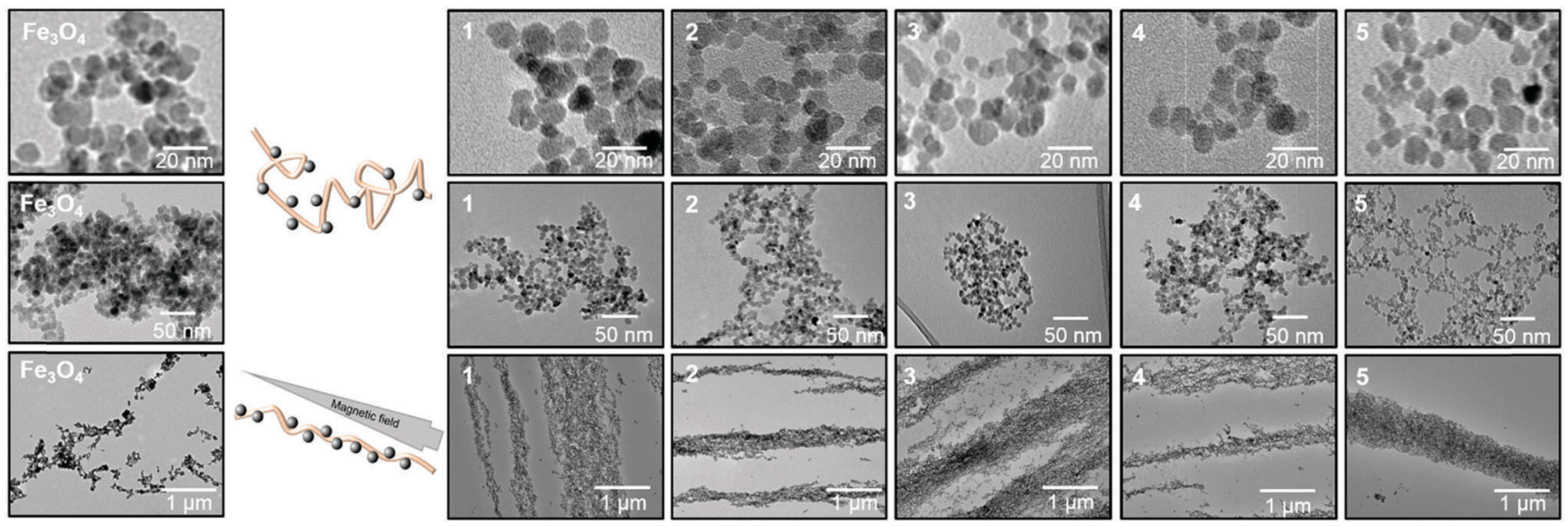

Fig. 5 Transmission electron microscope (TEM) images of non-stabilised $\mathrm{Fe}_{3} \mathrm{O}_{4}$ and heparin-stabilised $\mathrm{Fe}_{3} \mathrm{O}_{4}$ nanoparticles 1-5, labelled as prepared according to Table 1. Top row: images taken in the absence of a magnetic field at high magnification. Middle row: images taken in the absence of a magnetic field at low magnification. Bottom row: images taken in the presence of a parallel permanent magnetic field at low magnification. Schematics represent the behaviour of stabilised $\mathrm{Fe}_{3} \mathrm{O}_{4}$ particles in the absence and presence of a parallel magnetic field. 


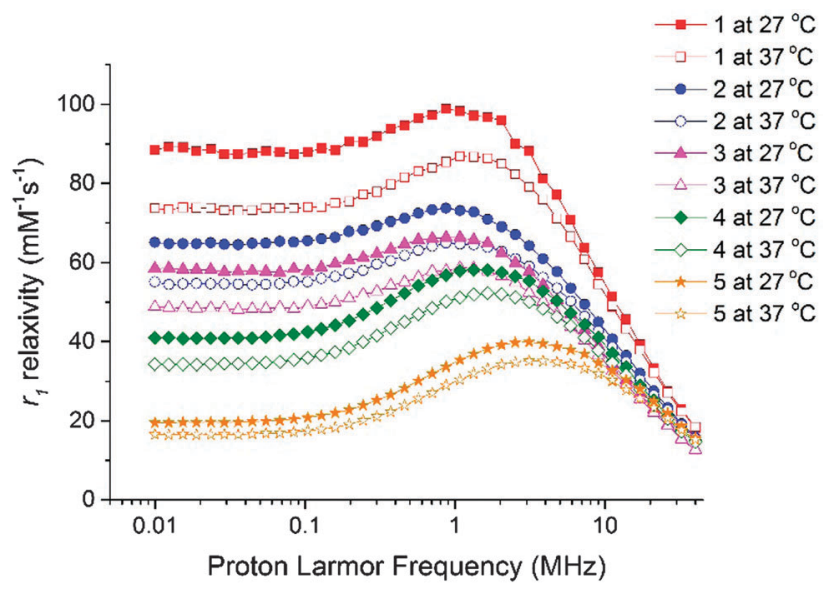

Fig. $7{ }^{1} \mathrm{H}$ NMRD profiles for heparin-stabilised $\mathrm{Fe}_{3} \mathrm{O}_{4}$ nanoparticles 1-5, prepared according to Table 1 . The $r_{1}$ values have been calculated in terms of [Fe] content of the samples. Profiles have been measured at two different temperatures, representative of room temperature $\left(27^{\circ} \mathrm{C}\right)$ and body temperature $\left(37^{\circ} \mathrm{C}\right)$.

charged backbone of heparin provides sites for seeding and formation of $\mathrm{Fe}_{3} \mathrm{O}_{4}$ nanoparticles. During synthesis, $\mathrm{Fe}^{\mathrm{II} / \mathrm{III}}$ ions associate with the negative sulfonate groups through electrostatic interactions. ${ }^{10,15}$ Co-precipitation then results in the formation of magnetite nanoparticles which remain strongly associated with these negative sites, enhancing their colloidal stability. In the presence of an external magnetic field, the dipoles of the superparamagnetic nanoparticles align in the direction of the applied magnetic field. The presence of the polyelectrolyte directs their self-assembly into 1-D linear arrays, ${ }^{11,15,37}$ structures which are reversible upon removal of the magnetic field, due to their superparamagnetic nature. Non-stabilised $\mathrm{Fe}_{3} \mathrm{O}_{4}$ particles showed significant aggregation in comparison. Application of a magnetic field resulted in some alignment, but arrays were nonlinear and disorganised aggregation was observed.

Average hydrodynamic diameters $\left(d_{\text {hyd }}\right)$ as measured by DLS (Table 1) were in the range $40-105 \mathrm{~nm}$, values significantly higher than those measured by TEM, due to hydrogen bonding and van der Waals interactions present as the particles, associated with long polymer chains, move according to Brownian motion in the aqueous phase. Particle $d_{\text {hyd }}$ generally increased with increasing amounts of polymer, as expected, due to increased inter-particle interactions between neighbouring polyelectrolyte chains which are expected to remain flexible in suspension and likely to interpenetrate. Polydispersity indices of $<0.2$ for all samples indicated the strong colloidal stability of these fluids (note that non-stabilised samples did not provide stable suspensions, therefore their $d_{\text {hyd }}$ characterisation details are omitted from Table 1).

To confirm their long-term aqueous stability, sample hydrodynamic diameters $\left(d_{\text {hyd }}\right)$ were measured daily over several days without disturbance; $d_{\text {hyd }}$ showed no significant changes over a 16 day period (Fig. 6). Fig. 6b also clearly shows the absence of precipitation in heparin-stabilised samples, whereas non-stabilised $\mathrm{Fe}_{3} \mathrm{O}_{4}$ particles quickly precipitate out of suspension.
Zeta potential measurements ( $\zeta$-potential, Table 1$)$ provide an indication of the surface charge of a species. The $\zeta$-potential of the reagents prior to reaction are shown in Table S1 (ESI $\dagger$ ). These demonstrate that, upon mixing and prior to co-precipitation, the positively charged $\mathrm{Fe}^{\mathrm{II} / \mathrm{III}}$ solutions and negatively charged heparin solutions are not simply mean values of the unmixed solutions. Their more positive values (than native heparin alone) indicate that iron ions are likely to be associating with the negatively charged backbone of the polyelectrolyte, as previously described. The prepared nanoparticle samples are strongly negatively charged (varying between -37 to $-17 \mathrm{mV}$, Table 1), due to the negative surface charge of the particle hydroxyl surface groups and the presence of the negative stabiliser in samples 1-5.

\section{Relaxometric behaviour}

NMRD has been widely used to demonstrate the efficacy of colloidal suspensions of magnetic nanoparticles as MRI CAs. ${ }^{8,13-17,38}$ The longitudinal proton nuclear relaxation rate of a colloidal system is influenced by the physical properties of a particle and its interaction with its surroundings (altering its rotational or translational molecular motions). It can therefore also be used to provide insights into the dynamic environment of hydrated nanostructured materials. ${ }^{13}$ NMRD profiles (Fig. 7) for the heparin-stabilised $\mathrm{Fe}_{3} \mathrm{O}_{4}$ samples, prepared according to Table 1, show typical superparamagnetic behaviour, corresponding well to theory. ${ }^{39}$ Profiles consist of a low field plateau, a mid-field peak in relaxation $\left(v_{\text {max }}\right)$, and a decrease in relaxivity $\left(r_{1}\right)$ at increasing field strengths. Relaxation behaviour in the high frequency region is based on Curie relaxation, a phenomenon caused by the appearance of a local magnetic field resulting from the application of an external magnetic field to paramagnetic ions. ${ }^{39}$ The relaxation in this region is determined primarily by the strength of moments and diffusional correlation times and tend to correlate with the $d_{\text {core }}$ size,${ }^{13}$ which is similar for all samples, therefore the profiles converge at $>20 \mathrm{MHz}$.

Low frequency behaviour (often referred to as the low field dispersion) is driven by random fluctuations of the nanoparticle moments (Néel relaxation) ${ }^{8}$ and is of critical importance to the shape of an NMRD profile. ${ }^{39,40}$ Herein, the low field relaxation plateau is observed to increase with increasing core particle size (and $M_{\mathrm{s}}$ ) and can be explained by the particles' anisotropy energy. The high values observed are indicative of the presence of nanoparticle assemblies, with magnetic anisotropy arising from strong dipole interactions due to their arrangement along the templating backbone of the polyelectrolyte stabiliser. This trend correlates with the increased density of particle nucleation along the polyelectrolyte backbone (dict. erat), with $r_{1}$ and $v_{\max }$ increasing (and $v_{\max }$ shifting to lower frequencies) with increasing Fe:Hep ratio, where more iron is available to participate in interparticle interactions. ${ }^{14}$ This agrees with previously observed behaviour for similar systems of colloidal $\gamma-\mathrm{Fe}_{2} \mathrm{O}_{3}$ indicating that low field relaxation increases with increasing particle size are limited by $M_{\mathrm{s}} \cdot{ }^{38}$ The theory is strictly limited to sub- $20 \mathrm{~nm}$ particles with uniaxial magnetocrystalline anisotropy and therefore it should be noted that this is not an infinitely expansive 
trend, as increasing cluster sizes have also been observed to result in decreased $r_{1}$ values; with relaxivity limited by the surface area to volume ratio of clusters, where central iron species contribute less to the relaxation behaviour. ${ }^{8}$ In the case of the samples analysed herein, particles remain small enough that this does not become an issue and stay within the domain of the theory. The observed parallel alignment of particles in the presence of an external magnetic field (Fig. 5) provides further corroboration of this, as high aspect ratio magnetic materials are known to possess larger dipole moments, providing the opportunity for strong dipole interactions and hence magnetic anisotropy. ${ }^{41}$

Relaxation behaviour for all samples was reduced at higher temperatures $\left(37^{\circ} \mathrm{C}\right)$, an effect which is particularly amplified at low field strengths (Fig. 7). This is a well-known phenomenon $^{15,42}$ which is associated with the altered behaviour of water at higher temperatures and its resulting effect on $\tau_{\mathrm{R}}, \tau_{\mathrm{m}}$ and $\tau_{\mathrm{D}}{ }^{43,44}$ It should be noted that non-stabilised $\mathrm{Fe}_{3} \mathrm{O}_{4}$ provides unreliable relaxation data due to its lack of aqueous colloidal stability and heparin does not contribute directly to relaxation behaviour due to its non-paramagnetic nature (as previously observed in magnetometry measurements).

The strong hydration of hydrophilic polyelectrolyte species may also result in changes in critical dynamic processes such as $\tau_{\mathrm{R}}, \tau_{\mathrm{m}}$ and $\tau_{\mathrm{D}}$ in composites formulated from them. Alteration of these correlation times is associated with an enhancement of the interaction of water with a CA. Such behaviour has been demonstrated to boost the $r_{1}$ relaxation behaviour of similar systems ${ }^{13,45}$ and systems designed to geometrically confine water. $^{46-48}$ An inverse correlation is observed between the hydrodynamic diameter $\left(d_{\text {hyd }}\right)$ and low field relaxivity of all the stabilised samples herein (Fig. 8). The higher surface area to volume ratio of the smaller species provides a higher surface area available for surface-water interactions. This correlates well with previous reports which demonstrated that microscopic

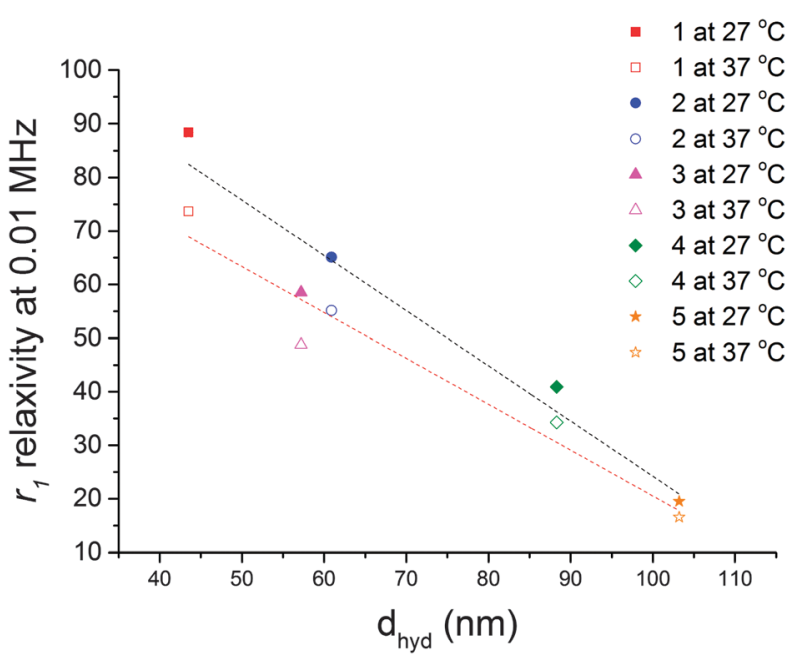

Fig. 8 Low frequency relaxivity $\left(r_{1}\right.$ at $0.01 \mathrm{MHz}$ at $27{ }^{\circ} \mathrm{C}$ (filled symbols) and $37{ }^{\circ} \mathrm{C}$ (open symbols)) of heparin-stabilised $\mathrm{Fe}_{3} \mathrm{O}_{4}$ nanoparticles 1-5, plotted as a function of hydrodynamic diameter $\left(d_{\text {hyd }}\right)$. Dotted lines represent a linear fit of data collected at $27^{\circ} \mathrm{C}$ (black) and $37^{\circ} \mathrm{C}$ (red).
Table 2 Relaxivity values of heparin-stabilised samples 1-5, prepared according to Table 1

\begin{tabular}{llll}
\hline Sample & $r_{1}{ }^{a}\left(\mathrm{mM}^{-1} \mathrm{~s}^{-1}\right)$ & $r_{2}{ }^{a}\left(\mathrm{mM}^{-1} \mathrm{~s}^{-1}\right)$ & $r_{2} / r_{1}$ ratio \\
\hline 1 & 42.9 & 181.5 & 4.2 \\
2 & 34.0 & 201.6 & 5.9 \\
3 & 32.3 & 172.2 & 5.3 \\
4 & 37.2 & 264.9 & 7.1 \\
5 & 23.1 & 139.9 & 6.1 \\
${ }^{a}$ Measured at $25^{\circ} \mathrm{C}$ at $13.2 \mathrm{MHz}$. & &
\end{tabular}

interactions between water and such nanocomposites are largely governed by hydrodynamic size. ${ }^{13,45}$

Transverse relaxation data ( $r_{2}$ relaxivity) was collected at a single field strength (13.2 MHz or $0.47 \mathrm{~T})$ at room temperature (Table 2) to provide further insight into the potential of these species as negative contrast agents. Since this mechanism of relaxation is governed by the dephasing of spins and is not proportional to the Larmor frequency, acquisition of data at multiple field strengths would not provide any further insights into particle behaviour. $r_{2}$ relaxivity is strong for all samples and follows a general inverse correlation with sample hydrodynamic diameter, similar to that observed for $r_{1}$ at low fields (in Fig. 8). This relationship follows the well-known Koenig-Keller model of $T_{2}$ relaxation, which shows an inverse relationship between relaxation and particle diameter, as this mechanism is dominated by diffusive outer sphere interactions. ${ }^{4,49}$ The high $r_{2} / r_{1}$ ratios observed for all samples demonstrate their strong potential as negative contrast agents.

\section{Thrombotic effect}

Heparin is a popular clinically-used anti-coagulant whose activity results from a conformational change upon binding to the enzyme inhibitor antithrombin III, which leads to deactivation of thrombin and other proteases (e.g. factor Xa) involved in blood clotting. As a known anti-coagulant, heparin (in sufficient quantity) may extend the plasma recalcification time (PRT) of blood. ${ }^{18}$ In order to determine whether the heparin-stabilised nanoparticles prepared herein affect blood thrombosis, particles were tested using a PRT assay (see Experimental section). Fig. 9 shows the time taken for a firm blood clot to form in the presence of control (water only), heparin, non-stabilised iron oxide nanoparticles and heparin-stabilised iron oxide nanoparticles. High concentrations of heparin $\left(0.5 \mathrm{mg} \mathrm{ml}^{-1}\right.$ to $\left.1 \mathrm{mg} \mathrm{ml}^{-1}\right)$ efficiently prevented the formation of a blood clot ( $>36 \mathrm{~h}$, not included in Fig. 9 for clarity); lower concentrations of heparin $\left(5 \mu \mathrm{g} \mathrm{ml} \mathrm{m}^{-1}\right)$, however, led to PRT similar to control samples $(296 \pm 24 \mathrm{~s})$. Non-stabilised nanoparticles $\left(50 \mu \mathrm{g} \mathrm{ml}^{-1}\right)$ demonstrated slightly shortened coagulation times (266 $\pm 1 \mathrm{~s}$, denoted by black stars), indicating that non-stabilised iron oxide nanoparticles increase the thrombotic effect, due to the adsorption of blood or blood components onto nanoparticle surfaces, speeding up the blood clotting process. ${ }^{18}$ Heparin-stabilised nanoparticles (samples 1-5) on the other hand, showed PRTs which were generally within error of the control samples (288-351 s). This is reasonable, due to the low concentrations of heparin used to stabilise the 


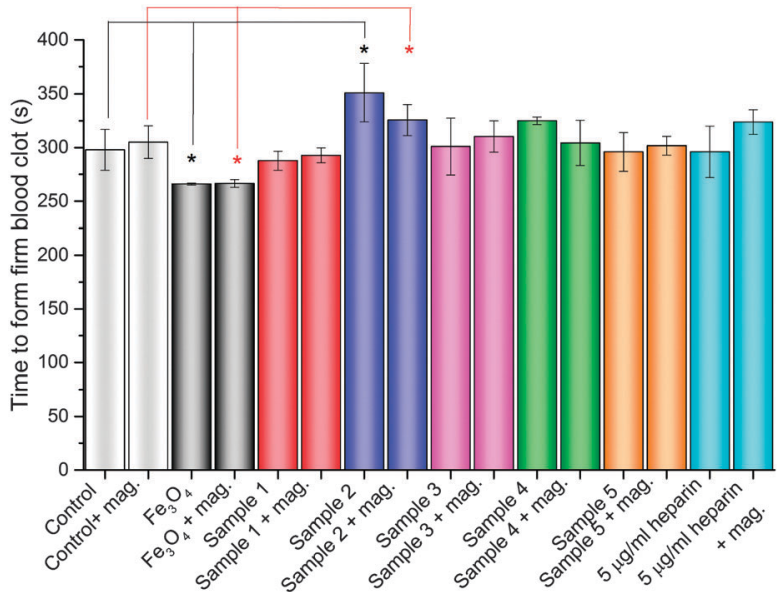

Fig. 9 Bar chart representation of the effect on time to form a firm blood clot of control (water only), non-stabilised $\mathrm{Fe}_{3} \mathrm{O}_{4}$ nanoparticles, heparinstabilised $\mathrm{Fe}_{3} \mathrm{O}_{4}$ nanoparticle samples 1-5, prepared according to Table 1 and a low concentration heparin solution; data collected in the absence and presence of a magnetic field (+mag.) as labelled. Results are represented as mean values based upon a minimum of 3 repetitions. Stars indicate statistically significant results $(P<0.05)$ compared to the control in the absence (black lines and stars) and presence (red lines and stars) of an external magnetic field.

nanoparticles not being high enough to lengthen the PRT, but providing stable colloids with coatings which are capable of preventing the adsorption of blood components which lead to accelerated PRT observed in the absence of stabiliser. Though there are a series of factors which can affect the antithrombotic efficiency of heparin, molecular weight is thought to be amongst the most important. High molecular weight $(>10 \mathrm{kDa})$ species, similar to those used herein, have low activity, due to differences in pharmacokinetic behaviour. ${ }^{50}$ Sample 2 showed slightly longer PRT than control samples (351 $\pm 27 \mathrm{~s}$, denoted by black stars), demonstrating that this sample has slightly increased anti-coagulation activity, which may be useful for in vivo applications. ${ }^{18}$ Similar behaviour was observed for all samples analysed in the presence of an external magnetic field. Non-stabilised $\mathrm{Fe}_{3} \mathrm{O}_{4}$ again shortened coagulation times, whereas sample 2 slightly lengthened coagulation times compared to the control, as before (denoted by red stars). Importantly, PRTs measured in the presence of a magnetic field were within error of values measured in the absence of a magnetic field for all samples, indicating that magnetically-induced alignment (observed in Fig. 5) does not induce undesirable thrombotic effects.

\section{Conclusions}

It has long been acknowledged that careful control during the preparation and assembly of nanomaterials can lead to improved properties. ${ }^{8,47}$ In particular, engineering of iron oxide nanostructured materials can boost their magnetic relaxation behaviour and hence MR imaging capabilities. Magnetic interactions between magnetic nanoparticles and water molecules is of critical importance to strong relaxation and is therefore key to the development of the next generation of MRI CAs. NMRD is a useful technique which can provide insights into such interactions. Its sensitivity to the solvation of nanostructures, the dynamic environment of nanoparticle assemblies and their interparticle interactions means that NMRD can provide unrivalled information.

Herein, we have demonstrated that careful control over the preparation of magnetite nanoparticles in the presence of a clinically approved polyelectrolyte species (heparin) can produce stable magnetic fluids with extremely high magnetic relaxation properties, particularly at low field strengths. When exploited as a stabiliser during the preparation of iron oxide nanoparticles, heparin behaves as a templating agent, whose negatively charged backbone provides sites for nanoparticles to seed and produce stable colloids. This results in nanoparticle assemblies with strong magnetic anisotropy arising from interparticle interactions, in turn leading to the observed boosts in low frequency relaxivity of stabilised samples, a trend which is mapped closely to the core size of the nanoparticles (and their saturation magnetisation). Due to the strong hydration of the iron oxide colloids, resulting from the hydrophilic stabilising species, an inverse correlation between hydrodynamic diameter and low field relaxivity is observed, with $r_{1}$ being limited by the hydrodynamic surface area.

Due to the range of field strengths over which data is collected in NMRD studies, it is of direct relevance for biomedical applications. When compared with some commercial iron oxide contrast agents and similarly-produced stabilised ferrites (prepared using non-clinically approved stabilisers), our magnetic fluids (the range of values achieved by samples $1-5$ has been included in Table 3) have superior $r_{1}$ and $r_{2}$ relaxivities and $r_{2} / r_{1}$ ratios higher than

Table 3 Relaxivity values $\left(r_{1}\right.$ and $\left.r_{2}\right)$ of commercial and literature examples of stabilised iron oxide nanoparticle samples compared to the heparinstabilised $\mathrm{Fe}_{3} \mathrm{O}_{4}$ nanoparticle samples $1-5$ prepared herein

\begin{tabular}{|c|c|c|c|}
\hline Sample & $r_{1}\left(\mathrm{mM}^{-1} \mathrm{~s}^{-1}\right)$ at $20 \mathrm{MHz}$ & $r_{2}\left(\mathrm{mM}^{-1} \mathrm{~s}^{-1}\right)$ at $20 \mathrm{MHz}$ & $r_{2} / r_{1}$ ratio at $20 \mathrm{MHz}$ \\
\hline Feridex ${ }^{\circledR 51}$ & $23.7^{a}$ & $107.0^{a}$ & 4.5 \\
\hline Resovist $^{\circledR 52}$ & $25.4^{a}$ & $151.0^{a}$ & 6.0 \\
\hline Sinerem ${ }^{\circledR 51}$ & $22.7^{a}$ & $53.1^{a}$ & 2.3 \\
\hline PSSS-stabilised $\mathrm{Fe}_{3} \mathrm{O}_{4}{ }^{15}$ & $22.5^{a, b}$ & $132.4^{a, b}$ & $5.9^{b}$ \\
\hline PSSS-stabilised $\mathrm{CoFe}_{2} \mathrm{O}_{4}{ }^{13}$ & $31.1^{c}$ & - & - \\
\hline Heparin-stabilised $\mathrm{Fe}_{3} \mathrm{O}_{4}{ }^{e}$ & $22.9-33.7^{a_{f} f}, 23.9-34.8^{d_{f} f}$ & $139.9-264.9^{c, g}$ & $4.2-7.1^{c, g}$ \\
\hline
\end{tabular}

${ }^{a}$ Measured at $37{ }^{\circ} \mathrm{C} .{ }^{b}$ Measured at 9 MHz. ${ }^{c}$ Measured at $25{ }^{\circ} \mathrm{C} .{ }^{d}$ Measured at $27{ }^{\circ} \mathrm{C} .{ }^{e}$ Relaxivity value ranges for samples $1-5 .{ }^{f}$ Measured by NMRD, extracted from Fig. $7 .{ }^{g}$ Measured at $13.2 \mathrm{MHz}$ (Table 2). 
those previously reported (Table 3), indicating that these species would be useful as negative contrast agents. Growing interest in ultra-low-field imaging (ULF-MRI) due to its lower costs, increased safety and mobility may lead to CAs which have high efficacy in these low fields becoming the next market-leaders.

The alignment of magnetite nanoparticles (aided by the templating stabiliser heparin) into 1-D linear arrays presents an interesting snapshot into particle behaviour in the presence of an applied magnetic field (such as that applied during MRI and NMRD measurements). Such magnetic particle alignment is not a new concept, however this structural behaviour corroborates NMRD evidence herein of strong magnetic anisotropic behaviour resulting from interparticle interactions. Further, large aspect ratio structures have been reported to provide advantages in nanosensor devices, flow cytometry and cellular payload delivery, where the 1-D morphology of nanocomposites facilitates easy passage through the circulatory system. ${ }^{15,53-57}$ Sub-200 nm particles are generally believed to be able to avoid uptake by the reticuloendothelial system (RES), with the addition of hydrophilic polymer coatings providing a 'masking' effect, aiding this evasion. ${ }^{18,19}$ Large aspect ratio 1-D nanostructures exhibit minimal macrophagic uptake, particularly under fluid flow conditions similar to those expected in the human circulatory system. ${ }^{58,59}$ As such, the 1-D nanocomposites formed in the presence of a magnetic field reported herein are not anticipated to accelerate recognition and uptake by the RES.

The prepared nanoparticles additionally have minimal effect on the coagulation behaviour of blood samples (whether in the absence or presence of an externally applied permanent magnetic field), serving to prevent unwanted acceleration of blood clotting which is triggered by the presence of nonstabilised $\mathrm{Fe}_{3} \mathrm{O}_{4}$ nanoparticles. ${ }^{18}$ This makes them promising as medical imaging agents, potentially circumventing previously reported issues with iron oxide-based MRI contrast agents. Collectively, the results presented herein indicate that our nanocomposites, fabricated from clinically-approved species, possess strong potential as the next generation of MRI contrast agents, particularly at low frequencies.

\section{Experimental}

All chemicals were used as supplied. $\mathrm{FeCl}_{2} \cdot 4 \mathrm{H}_{2} \mathrm{O}, \mathrm{FeCl}_{3} \cdot 6 \mathrm{H}_{2} \mathrm{O}$, $\mathrm{CaCl}_{2}, \mathrm{NaCl}$ and ammonium hydroxide (28 v/v\%) were purchased from Sigma-Aldrich. Heparin sodium salt (8-25 kDa) and blood collection tubes with clot activator were purchased from VWR UK and used as received. Fresh sheep's blood in Alsever's was purchased from TCS Biosciences and used as received. Ultrapure water was collected from a Millipore MilliQ system operated at $18.2 \mathrm{M} \Omega$.

Non-stabilised $\mathrm{Fe}_{3} \mathrm{O}_{4}$ nanoparticles were prepared using a co-precipitation technique. $\mathrm{FeCl}_{2} \cdot 4 \mathrm{H}_{2} \mathrm{O}(2.48 \mathrm{~g}, 12 \mathrm{mmol})$ and $\mathrm{FeCl}_{3} \cdot 6 \mathrm{H}_{2} \mathrm{O}(6.5 \mathrm{~g}, 24 \mathrm{mmol})$ were dissolved in $25 \mathrm{~mL}$ deoxygenated water (prepared by bubbling $\mathrm{N}_{2}$ for $\sim 20 \mathrm{~min}$ ); this solution was added dropwise to a deoxygenated $0.5 \mathrm{M}$ $\mathrm{NaOH}$ solution and stirred at $40{ }^{\circ} \mathrm{C}$ for $1 \mathrm{~h}$. The resulting brown precipitate was washed with Millipore water using centrifugation until the $\mathrm{pH}$ was neutral $(5 \times 25 \mathrm{ml})$. The precipitate was dried under vacuum and analysed.

Heparin stabilised $\mathrm{Fe}_{3} \mathrm{O}_{4}$ nanoparticles were prepared using an in situ co-precipitation technique. ${ }^{13} \mathrm{FeCl}_{2} \cdot 4 \mathrm{H}_{2} \mathrm{O}(0.4 \mathrm{~g}, 2 \mathrm{mmol})$ and $\mathrm{FeCl}_{3} \cdot 6 \mathrm{H}_{2} \mathrm{O}(1.08 \mathrm{~g}, 4 \mathrm{mmol})$ were dissolved in $100 \mathrm{~mL}$ deoxygenated water. Aliquots of this solution were added to aqueous deoxygenated heparin solutions of known concentrations (Table 1, $10 \mathrm{~mL}$ water). Ammonium hydroxide solution was added until the $\mathrm{pH}$ reached 11 . The solution was reacted at $40{ }^{\circ} \mathrm{C}$ with stirring for $2 \mathrm{~h}$. The resulting brown precipitate was washed with Millipore water using centrifugation until the $\mathrm{pH}$ was neutral $(5 \times 25 \mathrm{ml})$. The final washings were retained for NMRD analysis, as these were stable suspensions. The precipitate was dried under vacuum for analysis.

TEM images were obtained on a JEOL 2000fx microscope, $200 \mathrm{kV}, \mathrm{LaB}_{6}$ instrument operated with a beam current of $\sim 115 \mathrm{~mA}$; images were captured using a Gatan Orius 11 megapixel camera. Samples were prepared by deposition and drying of nanoparticle samples $(10 \mu \mathrm{L}$ of stock stable magnetic fluid suspensions) onto lacey carbon or formvar-coated 300-mesh copper TEM grids (Agar Scientific). Diameters were measured using ImageJ version 1.48a; average values were calculated by counting a minimum of 100 particles. Magnetically aligned samples were dried in the presence of a parallel permanent magnetic field $(\sim 0.1 \mathrm{~T})$.

Hydrodynamic particle size and zeta potential measurements were determined by Dynamic Light Scattering (DLS) using a Malvern Zetasizer Nano ZS instrument. A $4 \mathrm{~mW}$ He-Ne $633 \mathrm{~nm}$ laser module was used and scattered light was measured at $173^{\circ}$ (back scattering). The attenuator and position was selected automatically by the instrument and particle sizes reported as the average of 5 measurements. The long-term stability study was carried out by placing $1 \mathrm{~mL}$ of aqueous colloid (as prepared according to Table 1) into a $4.5 \mathrm{~mL}$ cuvette and measuring hydrodynamic diameter every day for several days with minimal disturbance. Samples were stored sealed at room temperature between measurements.

Fourier transform infrared (FTIR) spectra were acquired using a Bruker Vector 22 FTIR spectrometer with a Golden Gate diamond attenuated total reflection cell. A total of 64 scans were collected on solid samples after drying. X-ray powder diffraction was performed using a Bruker D5000 diffractometer with a $\mathrm{Cu} \mathrm{K} \alpha$ lamp. Raman spectra were collected using an inVia Raman microscope with a $785 \mathrm{~nm}$ solid state diode laser and $\times 50$ objective lens. Magnetisation measurements were carried out between -20 and 20 kOe in an Oxford Instruments vibrating sample magnetometer (VSM) or a Quantum Design Magnetic Property Measurement System (MPMS) superconducting quantum interference device magnetometer. Measurements ( $\mathrm{emu}^{-1}$ ) are based on the total mass of the sample measured; in the case of heparin-stabilised $\mathrm{Fe}_{3} \mathrm{O}_{4}$, this includes the mass contribution of non-magnetic heparin.

Measurement of ${ }^{1} \mathrm{H}$ NMRD profiles was performed on a Stelar Spinmaster FFC2000 $1 \mathrm{~T}$ instrument in the range of 0.01-40 MHz Larmor frequency at two different temperatures 
$\left(27^{\circ} \mathrm{C}\right.$ and $\left.37^{\circ} \mathrm{C}\right)$. The temperature was controlled using a Stelar VTC-91 airflow heater, equipped with a copper-constantan thermocouple; the temperature calibration in the probe head was carried out using a Delta OHM digital thermometer, with an absolute accuracy of $0.5{ }^{\circ} \mathrm{C}$. Fast field cycling (FFC) relaxometry was used to determine the longitudinal relaxation decay over a range of relaxation fields $(0.01-40 \mathrm{MHz})$. A set of 24 relaxation interval values (tau) allowed description of the spin-lattice decay curves for each relaxation field. A standard fitting algorithm (mono-exponential relaxation decay curve) allowed the evaluation of the relative longitudinal relaxation rate $\left(R_{1}=1 / T_{1}\right)$, which was converted to relaxivity using eqn (1).

Measurement of $r_{1}$ and $r_{2}$ values at a fixed field strength were carried out using a XiGo Nanotool with a resonant frequency of $13.2 \mathrm{MHz}$ operated at room temperature. For the measurement of $T_{1}$, the standard inversion-recovery method was employed with a typical $90^{\circ}$ pulse calibration of $250 \mu$ s with 4 scans per experiment; for $T_{2}$, the Carr-Purcell-MeiboomGill (CPMG) method was used with 4 scans per experiment. A minimum of 3 different concentrations of stable nanoparticle samples were prepared and relaxation time measured for each sample. $r_{1}$ and $r_{2}$ relaxivity values were calculated from curves plotted of $R_{1}\left(1 / T_{1}, \mathrm{~s}^{-1}\right)$ or $R_{2}\left(1 / T_{2}, \mathrm{~s}^{-1}\right) v s$. [Fe] concentration (mM, as measured by ICP-MS) and analysis of the slope of the line of best fit for each sample, with error measured from a minimum of 3 repetitions for each concentration point.

An Agilent 7500cx Inductively Coupled Plasma Mass Spectrometer (ICP-MS) was used to determine iron concentrations of stable aqueous suspensions of particles treated by hot nitric acid digestion. Concentrations as measured by this technique were used to normalise all relaxation data according to eqn (1).

Plasma recalcification times were monitored in order to determine the effect on blood clotting of the nanoparticle suspensions. Fresh sheep's blood $(0.1 \mathrm{~mL})$ was added directly to a clotting tube at $37{ }^{\circ} \mathrm{C}$, followed by either water, an aqueous solution of heparin ( $5 \mu \mathrm{g} \mathrm{ml}{ }^{-1}$ in water), non-stabilised $\mathrm{Fe}_{3} \mathrm{O}_{4}$ nanoparticles $\left(50 \mu \mathrm{g} \mathrm{ml}^{-1}\right.$ in water) or the as-prepared stable colloidal suspensions of nanoparticles prepared according to Table $1(0.1 \mathrm{~mL})$ and $\mathrm{CaCl}_{2}(0.1 \mathrm{~mL}, 0.025 \mathrm{M})$ and a stopwatch started. The clotting tube was tilted at $30 \mathrm{~s}$ intervals until a firm clot had formed. Samples tested in a magnetic field were subjected to an identical procedure in the presence of a magnetic field $(\sim 0.1 \mathrm{~T})$. The differences in the results obtained from nanoparticles (non-stabilised and stabilised) and controls were analysed statistically using the two-sample $t$-test $(P<0.05)$.

\section{Acknowledgements}

Thanks to Phil Aston assistance with ICP-MS measurements, Dr David Walker for assistance with XRD measurements and Dr Dani Gonzalez Santamaria and the Warwick Manufacturing group for access to the XiGo Nanotool. LT acknowledges the EPRSC-funded Molecular Organisation and Assembly in Cells Doctoral Training Centre. GLD acknowledges the Institute of Advanced Study, University of Warwick for a Global Research
Fellowship, the Royal Society, the Medical and Life Sciences Research Fund (Warwick) and the General Charities of the City of Coventry for bursaries supporting this research.

\section{References}

1 G.-L. Davies, I. Kramberger and J. J. Davis, Chem. Commun., 2013, 49, 9704-9721.

2 E. J. Werner, A. Datta, C. J. Jocher and K. N. Raymond, Angew. Chem., Int. Ed., 2008, 47, 8568-8580.

3 P. Caravan, Chem. Soc. Rev., 2006, 35, 512-523.

4 H. B. Na, I. C. Song and T. Hyeon, Adv. Mater., 2009, 21, 2133-2148.

5 C. C. Berry, J. Phys. D: Appl. Phys., 2009, 42, 224003.

6 C. C. Berry and A. S. G. Curtis, J. Phys. D: Appl. Phys., 2003, 36, R198.

7 Q. A. Pankhurst, N. K. T. Thanh, S. K. Jones and J. Dobson, J. Phys. D: Appl. Phys., 2009, 42, 224001.

8 C. J. Meledandri and D. F. Brougham, Anal. Methods, 2012, 4, 331-341.

9 A. M. G. C. Dias, A. Hussain, A. S. Marcos and A. C. A. Roque, Biotechnol. Adv., 2011, 29, 142-155.

10 J.-F. Berret, N. Schonbeck, F. Gazeau, D. El Kharrat, O. Sandre, A. Vacher and M. Airiau, J. Am. Chem. Soc., 2006, 128, 1755-1761.

11 R. Sheparovych, Y. Sahoo, M. Motornov, S. Wang, H. Luo, P. N. Prasad, I. Sokolov and S. Minko, Chem. Mater., 2006, 18, 591-593.

12 S. J. Byrne, S. A. Corr, Y. K. Gun'ko, J. M. Kelly, D. F. Brougham and S. Ghosh, Chem. Commun., 2004, 2560-2561.

13 G.-L. Davies, S. A. Corr, C. J. Meledandri, L. Briode, D. F. Brougham and Y. K. Gun'ko, ChemPhysChem, 2011, 12, 772-776.

14 S. A. Corr, Y. Gun'ko, R. Tekoriute, C. J. Meledandri and D. F. Brougham, J. Phys. Chem. C, 2008, 112, 13324-13327.

15 S. A. Corr, S. J. Byrne, R. Tekoriute, C. J. Meledandri, D. F. Brougham, M. Lynch, C. Kerskens, L. O'Dwyer and Y. K. Gun'ko, J. Am. Chem. Soc., 2008, 130, 4214-4215.

16 A. Ouakssim, A. Roch, C. Pierart and R. N. Muller, J. Magn. Magn. Mater., 2002, 252, 49-52.

17 A. Roch, R. N. Muller and P. Gillis, J. Chem. Phys., 1999, 110, 5403-5411.

18 S. C. Wuang, K. G. Neoh, E. T. Kang, D. W. Pack and D. E. Leckband, Adv. Funct. Mater., 2006, 16, 1723-1730.

19 C. D. Walkey, J. B. Olsen, H. Guo, A. Emili and W. C. W. Chan, J. Am. Chem. Soc., 2011, 134, 2139-2147.

20 A. S. Wadajkar, S. Santimano, M. Rahimi, B. Yuan, S. Banerjee and K. T. Nguyen, Biotechnol. Adv., 2013, 31, 504-513.

21 K. R. Di Bona, Y. Xu, P. A. Ramirez, J. DeLaine, C. Parker, Y. Bao and J. F. Rasco, Reprod. Toxicol., 2014, 50, 36-42.

22 Y. H. Hwang and D. Y. Lee, Quantitative Imaging in Medicine and Surgery, 2012, 2, 118-123.

23 A. Javid, S. Ahmadian, A. A. Saboury, S. M. Kalantar and S. Rezaei-Zarchi, RSC Adv., 2014, 4, 13719-13728. 
24 J. Zhang, M. C. Shin, A. E. David, J. Zhou, K. Lee, H. He and V. C. Yang, Mol. Pharmaceutics, 2013, 10, 3892-3902.

25 M. J. Jung, S. S. Lee, Y. H. Hwang, H. S. Jung, J. W. Hwang, M. J. Kim, S. Yoon and D. Y. Lee, Biomaterials, 2011, 32, 9391-9400.

26 S. H. Yuk, K. S. Oh, S. H. Cho, B. S. Lee, S. Y. Kim, B.-K. Kwak, K. Kim and I. C. Kwon, Biomacromolecules, 2011, 12, 2335-2343.

27 M. S. Thu, L. H. Bryant, T. Coppola, E. K. Jordan, M. D. Budde, B. K. Lewis, A. Chaudhry, J. Ren, N. R. S. Varma, A. S. Arbab and J. A. Frank, Nat. Med., 2012, 18, 463-467.

28 J.-H. Lee, M. J. Jung, Y. H. Hwang, Y. J. Lee, S. Lee, D. Y. Lee and H. Shin, Biomaterials, 2012, 33, 4861-4871.

29 Y. Wang, B. Li, Y. Zhou and D. Jia, Nanoscale Res. Lett., 2009, 4, 1041-1046.

30 I. Chamritski and G. Burns, J. Phys. Chem. B, 2005, 109, 4965-4968.

31 O. N. Shebanova and P. Lazor, J. Solid State Chem., 2003, 174, 424-430.

32 P. R. Graves, C. Johnston and J. J. Campaniello, Mater. Res. Bull., 1988, 23, 1651-1660.

33 A. Bava, F. Cappellini, E. Pedretti, F. Rossi, E. Caruso, E. Vismara, M. Chiriva-Internati, G. Bernardini and R. Gornati, BioMed Res. Int., 2013, 2013, 10.

34 A. K. Gupta and S. Wells, IEEE Transactions on Nanobioscience, 2004, 3, 66-73.

35 A. K. Gupta and M. Gupta, Biomaterials, 2005, 26, 3995-4021.

36 L. C. Varanda, M. Jafelicci, P. Tartaj, K. O’Grady, T. GonzálezCarreño, M. P. Morales, T. Muñoz and C. J. Serna, J. Appl. Phys., 2002, 92, 2079-2085.

37 J. Sun, Y. Zhang, Z. Chen, J. Zhou and N. Gu, Angew. Chem., Int. Ed., 2007, 46, 4767-4770.

38 C. J. Meledandri, J. K. Stolarczyk, S. Ghosh and D. F. Brougham, Langmuir, 2008, 24, 14159-14165.

39 A. Roch, R. N. Muller and P. Gillis, J. Chem. Phys., 1999, 110, 5403-5411.

40 Advances in Inorganic Chemistry: Relaxometry of Water-Metal Ion Interactions, ed. R. van Eldik and I. Bertini, Elsevier Academic Press, 2005.

41 M. Chen, L. Sun, J. E. Bonevich, D. H. Reich, C. L. Chien and P. C. Searson, Appl. Phys. Lett., 2003, 82, 3310-3312.
42 E. Toth, R. D. Bolskar, A. Borel, G. Gonzalez, L. Helm, A. E. Merbach, B. Sitharaman and L. J. Wilson, J. Am. Chem. Soc., 2005, 127, 799-805.

43 T. Kawaguchi, A. Yoshino, M. Hasegawa, T. Hanaichi, S. Maruno and N. Adachi, J. Mater. Sci.: Mater. Med., 2002, 13, 113-117.

44 V. Jacques, S. Dumas, W.-C. Sun, J. S. Troughton, M. T. Greenfield and P. Caravan, Invest. Radiol., 2010, 45, 613-624.

45 C. J. Meledandri, T. Ninjbadgar and D. F. Brougham, J. Mater. Chem., 2011, 21, 214-222.

46 J. S. Ananta, B. Godin, R. Sethi, L. Moriggi, X. Liu, R. E. Serda, R. Krishnamurthy, R. Muthupillai, R. D. Bolskar, L. Helm, M. Ferrari, L. J. Wilson and P. Decuzzi, Nat. Nanotechnol., 2010, 5, 815-821.

47 J. J. Davis, W.-Y. Huang and G.-L. Davies, J. Mater. Chem., 2012, 22, 22848-22850.

48 W.-Y. Huang, G.-L. Davies and J. J. Davis, Chem. Commun., 2013, 49, 60-62.

49 S. H. Koenig and K. E. Kellar, Magn. Reson. Med., 1995, 34, 227-233.

50 R. Al Dieri, R. Wagenvoord, G. W. K. Van Dedem, S. Beguin and H. C. Hemker, J. Thromb. Haemostasis, 2002, 1, 907-914.

51 C. W. Jung and P. Jacobs, Magn. Reson. Imaging, 1995, 13, 661-674.

52 C. F. G. C. Geraldes and S. Laurent, Contrast Media Mol. Imaging, 2009, 4, 1-23.

53 Y. Cui, Q. Wei, H. Park and C. M. Lieber, Science, 2001, 293, 1289-1292.

54 G. Tong, J. Guan and Q. Zhang, Adv. Funct. Mater., 2013, 23, 2406-2414.

55 D. Fan, Z. Yin, R. Cheong, F. Q. Zhu, R. C. Cammarata, C. L. Chien and A. Levchenko, Nat. Nanotechnol., 2010, 5, 545-551.

56 A. Prina-Mello, A. M. Whelan, A. Atzberger, J. E. McCarthy, F. Byrne, G.-L. Davies, J. M. D. Coey, Y. Volkov and Y. K. Gun'ko, Small, 2010, 6, 247-255.

57 J. Jiménez, R. Sheparovych, M. Pita, A. Narvaez García, E. Dominguez, S. Minko and E. Katz, J. Phys. Chem. C, 2008, 112, 7337-7344.

58 Y. Geng, P. Dalhaimer, S. Cai, R. Tsai, M. Tewari, T. Minko and D. E. Discher, Nat. Nanotechnol., 2007, 2, 249-255.

59 P. Chaudhuri, R. Harfouche, S. Soni, D. M. Hentschel and S. Sengupta, ACS Nano, 2010, 4, 574-582. 